\title{
Zinc Undecylenate
}

National Cancer Institute

\section{Source}

National Cancer Institute. Zinc Undecylenate. NCI Thesaurus. Code C29552.

A natural or synthetic fungistatic fatty acid, antifung al Zinc Undecylenate is used topically in creams against fungal infections, eczemas, ringworm, and other cutaneous conditions. The zinc provides an astringent action, reducing rawness and irritation. ( $\mathrm{NCI04)}$ 